\title{
Hypoglycemic activity of aqueous leaf extract of Persea americana Mill
}

Persea americana mill (lauraceae) is a tree plant also called avocado or alligator pear. It is chiefly grown in temperate regions and sparsely grown in tropical regions of the world. It is recommended for anemia, exhaustion, hypercholesterolemia, hypertension, gastritis, and gastroduodenal ulcer. ${ }^{[1]}$ The leaves have been reported as an effective antitussive, antidiabetic, and relief for arthritis pain by traditional medicine practitioners of Ibibio tribe in South Nigeria. Analgesic and antiinflammatory properties of the leaves have been reported. ${ }^{[2]}$ Although there are reports of the medicinal uses of this plant, there is no report on its antidiabetic activity. Therefore, it was thought worthwhile to evaluate its antidiabetic effects in alloxan-induced diabetic rats.

In November 2004, the fresh leaves of Persea americana were collected from the farm of the Faculty of Agriculture, University of Uyo, Uyo, Nigeria. The plant was identified and authenticated by Dr. (Mrs) Margaret Bassey, a taxonomist in the Department of Botany, University of Uyo, Uyo, Nigeria.

The leaves were shade dried for a period of 10 days. It was pulverized in wooden mortar and $100 \mathrm{~g}$ of the powder was macerated in $300 \mathrm{~mL}$ of water in a conical flask for $72 \mathrm{~h}$. The liquid filtrate was concentrated in vacuo at $40{ }^{\circ} \mathrm{C}$. The yield was $2.67 \%$. The dried extract was formulated as suspension in distilled water using Tween 80 as suspending agent. The extract was chemically tested for the presence of different chemical constituents using standard methods. ${ }^{[3]}$

Adult albino Wistar rats (150-180 g) of either sex obtained from University of Uyo, animal house, Uyo, Nigeria were used for the study. The animals were acclimatized for a period of 10 days to room temperature $\left(28 \pm 5{ }^{\circ} \mathrm{C}\right)$ with a relative humidity of $50 \%$. They were housed in standard cages and maintained on standard pellets and water ad libitum. Approval for animal studies were obtained from the College of Health Sciences Animal Ethics Committee, University of Uyo.
Alloxan monohydrate (BDH) $150 \mathrm{mg} / \mathrm{kg}$, body weight was dissolved in normal saline and injected intraperitoneally after $18 \mathrm{~h}$ fasting to induce hyperglycemia. ${ }^{[4]}$ After 1 hour of alloxan administration the animals were fed on standard pellets and water ad libitum. The experimental animals were fasted for $18 \mathrm{~h}$ before alloxan injection. The blood glucose level (BGL) was monitored after alloxanization in blood samples collected by tail tipping method using a glucometer. ${ }^{[5]}$ After $72 \mathrm{~h}$, the rats having BGL above $150 \mathrm{mg} / \mathrm{dL}$ of blood were selected for the study and divided into five groups (A to E) of five rats each. The extract 100, 150 and $200 \mathrm{mg} / \mathrm{kg}$, was administered orally to groups A, B and C respectively. The reference drug chlorpropamide $(100 \mathrm{mg} / \mathrm{kg})$ and vehicle were also administered orally to animals in groups D and E representing the reference and control groups, respectively. The above treatments were carried out in each group of animals for 7 consecutive days. The blood glucose level was monitored after 1, 3, 6 and $12 \mathrm{~h}$ of administration of a single dose of the extract (for acute study), and at the end of 1, 2, 3, and 7 days (for prolonged treatment).

Data obtained was subjected to two-way analysis of variance followed by Dunnett's test to determine the statistical significance of the change in BGL. $\mathrm{P}<0.01$ was considered significant.

The result of the phytochemical screening of the aqueous leaf extract of Persea americana revealed that the extract contained various pharmacologically active compounds such as saponins, tannins, phlobatannins, flavonoids, alkaloids, and polysaccharides. The results of the evaluation of antidiabetic activity of the extract are summarized as the change in BGL in tables 1 and 2 . The administration of aqueous extract of $P$. americana (100-200 mg/kg) to alloxan-diabetic rats produced a significant reduction $(\mathrm{P}<0.01)$ in BGL in a dose-dependent fashion after a single dose of the extract, as well as following

Table 1

Effect of $P$. americana on blood glucose levels of alloxan diabetic rats after a single dose

\begin{tabular}{|c|c|c|c|c|c|c|}
\hline \multirow[t]{2}{*}{ Drug } & \multirow{2}{*}{$\begin{array}{l}\text { Dose } \\
\mathrm{mg} / \mathrm{kg}\end{array}$} & \multirow[b]{2}{*}{ Initial } & \multicolumn{4}{|c|}{ Blood glucose level $\mathrm{mg} / \mathrm{dl}($ Mean $\pm S D)$} \\
\hline & & & $1 h$ & $3 h$ & $6 h$ & $12 h$ \\
\hline Control & - & $222.1 \pm 1.3$ & $216.7 \pm 15.3$ & $219.2 \pm 20.5$ & $221.3 \pm 4.8$ & $225.0 \pm 6.7$ \\
\hline \multirow{2}{*}{ Extract ( $P$. Americana) } & 150 & $226.3 \pm 0.8$ & $205.8 \pm 16.8$ & $150.9 \pm 20.3$ & $131.3 \pm 11.3^{*}$ & $175.0 \pm 10.1^{*}$ \\
\hline & 200 & $223.3 \pm 2.1$ & $201.6 \pm 15.6$ & $130.4 \pm 13.4^{*}$ & $118.0 \pm 9.3^{*}$ & $151.3 \pm 23.2^{*}$ \\
\hline Chlorpropamide & 100 & $225.4 \pm 2.5$ & $196.3 \pm 18.8$ & $119.5 \pm 15.0^{*}$ & $107.3 \pm 7.1^{*}$ & $137.8 \pm 22.1^{*}$ \\
\hline
\end{tabular}

${ }^{*} \mathrm{P}<0.01$ Vs control, $\mathrm{n}=5$ in each group. $\mathrm{F}=7.03$ and $60.8 ; \mathrm{df}=24,4 ; \mathrm{P}<0.001$ (Two-way ANOVA). 
Table 2

Effect of $P$. americana on blood glucose levels of alloxan diabetic rats after prolonged treatment.

\begin{tabular}{|c|c|c|c|c|c|c|}
\hline Drug & $\begin{array}{l}\text { Dose } \\
\mathrm{mg} / \mathrm{kg}\end{array}$ & Initial & \multicolumn{4}{|c|}{ Blood glucose level $\mathrm{mg} / \mathrm{dl}($ Mean $\pm S D)$} \\
\hline Control & - & $222.0 \pm 1.3$ & $231.2 \pm 23.1$ & $191.3 \pm 16.4$ & $181.3 \pm 16.1$ & $175.3 \pm 3.8$ \\
\hline \multirow{2}{*}{ Extract } & 150 & $226.3 \pm 0.8$ & $195.4 \pm 17.3^{*}$ & $130.3 \pm 20.3^{*}$ & $92.1 \pm 15.2^{*}$ & $72.3 \pm 12.2$ \\
\hline & 200 & $223.3 \pm 2.1$ & $189.3 \pm 18.3^{*}$ & $129.1 \pm 10.1^{*}$ & $87.3 \pm 13.1^{*}$ & $69.2 \pm 6.7^{*}$ \\
\hline
\end{tabular}

prolonged treatment (7 days) compared to the control group. Maximum antidiabetic activity was reached at $6 \mathrm{~h}$ after a single dose of the extract, producing $60.02 \pm 6.83 \%$ reduction in blood glucose levels. However, the hypoglycemic effect of the extract was incomparable to that of the reference drug (chlorpropamide) (Table 1). The extract (100-200 mg/kg) produced a sustained significant $(\mathrm{P}<0.01)$ antidiabetic activity during prolonged treatment (7 days). A sustained significant $(\mathrm{P}<0.01)$ reduction in the blood glucose levels of the treated rats was observed throughout the period of treatment. The hypoglycemic effect was not comparable to that of the reference group (Table 2).

The observation confirms the use of this plant in ethnomedical practice for diabetes management and demonstrated that long-term treatment for 7 days was more effective than single dose acute treatment. This study warrants the investigation to isolate and identify the hypoglycemic principles and to elucidate their exact mechanism of action.

\section{B.S. Antia, J.e. Okokon*, P.A. Okon}

Department of Chemistry, University of Uyo, Uyo - Nigeria, *Department of Pharmacology and Toxicology, Faculty of Pharmacy, University of Uyo, Uyo - Nigeria E-mail: judeefiom@yahoo.com

\section{References}

1. Pamplona- Roger GD. Encyclopedia of Medicinal Plant. Vol. 2. Spain: Grafica Reunide; 1999.

2. Adeyemi $\mathrm{OO}, \mathrm{Okpo} \mathrm{SO}$, Ogunti, OO. Analgesic and anti-inflammatory effects of some aqueous extracts of leaves of Persea americana Mill (Lauraceae). Fitoterapia 2002;73:375-80.

3. Trease GE, Evans WC. Pharmacognosy. $13^{\text {th }}$ ed. London: Bailliere Tindall; 1983.

4. Yanarday R, Colak H. Effect of chard (Beta vulgaris L. Var cicla) on blood glucose levels in normal and alloxan-induced diabetic rabbits. Pharm Pharmacol Comm 1998;4:309-11.

5. World Health Organisation Expert Committee on diabetes mellitus.Tech Rep Series 1980.

\title{
NATIONAL SEMINAR ON EMERGING TRENDS IN ETHNOPHARMACOLOGY
}

\author{
Date : Novermber $12-13^{\text {th }}, 2005$ \\ Venue : H.S.K. College of Pharmacy, Bagalkot - 587 101, Karnataka
}

\section{Contact:}

Prof. I.S. MUCHANDI

Chairman, National Seminar-2005

H.S.K. College of Pharmacy,

B.V.V.S. Campus, Bagalkot-587 101, Karnataka

E-mail: hskcop@rediffmail.com 